\title{
The epidemiological burden of obesity in childhood: a worldwide epidemic requiring urgent action
}

\author{
Mariachiara Di Cesare ${ }^{1 *}$, Maroje Soric ${ }^{2,3}$, Pascal Bovet ${ }^{4,5}$, J Jaime Miranda ${ }^{6}$, Zulfiqar Bhutta ${ }^{7}$, Gretchen A Stevens ${ }^{8,9}$, \\ Avula Laxmaiah ${ }^{10}$, Andre-Pascal Kengne $^{11}$ and James Bentham ${ }^{12^{*}}$
}

\begin{abstract}
Background: In recent decades, the prevalence of obesity in children has increased dramatically. This worldwide epidemic has important consequences, including psychiatric, psychological and psychosocial disorders in childhood and increased risk of developing non-communicable diseases (NCDs) later in life. Treatment of obesity is difficult and children with excess weight are likely to become adults with obesity. These trends have led member states of the World Health Organization (WHO) to endorse a target of no increase in obesity in childhood by 2025.

Main body: Estimates of overweight in children aged under 5 years are available jointly from the United Nations Children's Fund (UNICEF), WHO and the World Bank. The Institute for Health Metrics and Evaluation (IHME) has published country-level estimates of obesity in children aged 2-4 years. For children aged 5-19years, obesity estimates are available from the NCD Risk Factor Collaboration. The global prevalence of overweight in children aged 5 years or under has increased modestly, but with heterogeneous trends in low and middle-income regions, while the prevalence of obesity in children aged 2-4 years has increased moderately. In 1975, obesity in children aged 5-19years was relatively rare, but was much more common in 2016.

Conclusions: It is recognised that the key drivers of this epidemic form an obesogenic environment, which includes changing food systems and reduced physical activity. Although cost-effective interventions such as WHO 'best buys' have been identified, political will and implementation have so far been limited. There is therefore a need to implement effective programmes and policies in multiple sectors to address overnutrition, undernutrition, mobility and physical activity. To be successful, the obesity epidemic must be a political priority, with these issues addressed both locally and globally. Work by governments, civil society, private corporations and other key stakeholders must be coordinated.
\end{abstract}

Keywords: Obesity, Overweight, Global health, Children, Adolescents

\section{Background}

Excess weight during childhood and adolescence remains one of the most important issues in global health, despite emerging as a concern several decades ago $[1,2]$. Recent estimates suggest that 40 million children under the age of 5 years and more than 330 million children and adolescents aged 5-19years were overweight or obese in 2016 [3]. Given the global emergency posed by

\footnotetext{
* Correspondence: c.dicesare@mdx.ac.uk; j.bentham@kent.ac.uk

${ }^{1}$ Middlesex University, The Burroughs, London NW4 4BT, UK

${ }^{12}$ University of Kent, Giles Lane, Canterbury CT2 7NZ, UK

Full list of author information is available at the end of the article
}

excess weight in children, member states of the World Health Organization (WHO) endorsed "no increase in childhood overweight by 2025 " as one of the six global nutrition targets in the 'Comprehensive Implementation Plan for Maternal, Infant and Young Child Nutrition' [4]. This is consistent with the same target for obesity and diabetes between 2010 and 2025 in the 'WHO Global Action Plan for the Prevention and Control of Non-communicable Diseases 2013-2020' [5, 6].

Overweight or obesity during childhood has important short-term and long-term consequences. In the short term, children who are overweight or obese are more

(c) The Author(s). 2019 Open Access This article is distributed under the terms of the Creative Commons Attribution 4.0 International License (http://creativecommons.org/licenses/by/4.0/), which permits unrestricted use, distribution, and reproduction in any medium, provided you give appropriate credit to the original author(s) and the source, provide a link to the Creative Commons license, and indicate if changes were made. The Creative Commons Public Domain Dedication waiver (http://creativecommons.org/publicdomain/zero/1.0/) applies to the data made available in this article, unless otherwise stated. 
likely to suffer from psychological comorbidities such as depression, anxiety, low self-esteem, a series of emotional and behavioural disorders [7, 8], asthma [9], lowgrade systemic inflammation [10,11], liver complications $[12,13]$, and musculoskeletal problems, especially in the lower extremities [14]. Children who are overweight and obese also have more metabolic and cardiovascular risk factors [15, 16], such as high blood pressure [17], dyslipidaemia [18], type 2 diabetes [19] and other abnormalities of the cardiovascular system [20]. In the long term, overweight or obesity during childhood increases the risk of developing cardiovascular diseases, diabetes, some cancers, and musculoskeletal disorders in adulthood, which can lead to disability [21] and premature death [22-24]. In addition, the treatment of obesity in adulthood is difficult [25], with evidence suggesting that around three-quarters of children who are overweight or obese carry this status into adulthood [26]. Strong persistence of overweight status and low efficacy of available treatments highlight the need to prevent overweight and obesity at the earliest possible stage of life.

It is recognised that weight gain is partly caused by elevated energy intake, which often includes a disproportionate amount of refined carbohydrates and/or processed foods (increasing insulin release and fat storage), and decreased physical activity [27]. Weight gain is also promoted by environmental, behavioural, biological, and genetic factors, whose interactions have driven the current levels of worldwide obesity. Maternal health status during pregnancy, an obese intrauterine environment [28] and rapid changes in weight status during infancy [29] are other factors contributing to obesity in children. Moreover, the expanding 'obesogenic' environment increases the propensity of children to consume foods and beverages that are high in calories, energy-dense, or low in nutrients, as well as promoting sedentary lifestyles through reductions in opportunities for active mobility in daily lives [30]. Key drivers of the rapidly increasing worldwide occurrence of obesity and diabetes across populations are the globalised market and commercial interests that favour the production and distribution of inexpensive, energy-dense foods and beverages and limited political will to address the economic causes of the obesity epidemic [3], which include a strong association with socioeconomic inequalities [31, 32]. In high-income settings, higher prevalence of obesity is observed in disadvantaged and marginalised communities than in groups with higher socioeconomic status [33-35]. In contrast, higher prevalence of obesity is seen in groups with higher socioeconomic status in some, but not all, low and middle-income settings [31].

Over the past decade, genome-wide association studies have been used to identify genetic markers that increase predisposition to weight gain, with the goal of explaining the biological mechanisms leading to obesity. For example, the FTO gene is recognised as being key to the regulation of energy intake, with variants predisposing individuals to greater caloric intake and reduced feelings of satiety [36]. Genetic and epigenetic factors also produce heterogeneity in obesity phenotypes across populations, including characteristic metabolic profiles and greater central body adiposity in south Asians [37]. However, groups with almost identical genotypes can have very different obesity phenotypes, as shown by the large differences in prevalence between Samoa and American Samoa [38]. In addition, obesity-associated genes cannot explain the rapid onset and scale of the current obesity epidemic, even if genetic predisposition makes some individuals more susceptible to the obesogenic environment [39].

Finally, obesity in childhood has important economic and social costs, with increased burdens on health systems as well as later reduced economic productivity [40-43]. For example, in the USA, the estimated direct medical cost over the lifetime of a 10-year-old child with obesity, compared with a similar child with normal weight and allowing for weight gain in adulthood, is between US\$12,660 and US\$19,630 [44].

Over the past decade, there has been a global effort to provide reliable and detailed estimates of the worldwide epidemic of excess weight in children and adolescents. Here, we aim to provide a comprehensive description of this work, presenting global, regional and national trends based on the most up-to-date information available. To do so, we use data from the United Nations Children's Fund (UNICEF)/WHO/World Bank Joint Child Malnutrition Estimates [45], the Institute for Health Metrics and Evaluation (IHME) Global Burden of Disease Study [46] and the Non-Communicable Disease (NCD) Risk Factor Collaboration (NCD-RisC) [47] (see Table 1). It should be noted that there are two definitions of obesity in childhood: the International Obesity Taskforce (IOTF) definition [48] and one based on the WHO growth reference

Table 1 Definitions of overweight and obesity in different studies

\begin{tabular}{lllll}
\hline Metric & Age group & Source & Definition & Years \\
\hline Overweight & Under 5 years & UNICEF, WHO, World Bank [45] & WHO Child Growth Standard & 1990-2018 \\
Obesity & 2-4 years & IHME [46] & International Obesity Task Force & 1980-2015 \\
Obesity & 5-19years & NCD-RisC [47] & WHO Growth Reference & 1975-2016 \\
\hline
\end{tabular}

Abbreviations: IHME Institute for Health Metrics, NCD-RisC Non-Communicable Disease Risk Factor Collaboration, UNICEF United Nations Children's Fund, WHO World Health Organization 
curve [49]. They have different age-specific cut-offs and can therefore give different obesity estimates for a given set of data. In the following, estimates published by IHME use the IOTF definition, while estimates published by UNICEF/WHO/World Bank and NCD-RisC use the WHO growth reference. Readers interested in the differences in statistical models and regional definitions in these studies are referred to the original papers.

\section{Children aged 5 years or under}

\section{Global and regional trends in overweight}

The most recent estimates of trends in overweight for children under the age of 5 years were published jointly by UNICEF, WHO and the World Bank in April 2019 [45]. Globally, the prevalence of overweight rose modestly, from $4.8 \%$ in 1990 to $5.9 \%$ in 2018 , but with estimates for low and middle-income United Nations regions showing heterogeneous trends. Estimates were not published for high-income regions.

Table 2 presents results by region. In Africa as a whole, overweight prevalence changed little between 1990 and 2018. However, prevalence increased in Northern and Southern Africa, and also rose modestly in Middle Africa. This was offset by decreases in overweight prevalence in Eastern and Western Africa. Overweight prevalence in Asia rose, with increases in every region except Eastern Asia, where overweight prevalence remained almost unchanged. In Latin America and the Caribbean, overweight prevalence increased, including a moderate increase in the Caribbean and small increases in Central and South
America. Finally, the overweight epidemic in Oceania (excluding Australia and New Zealand) became much more severe, with a three-fold increase in prevalence.

\section{Trends in obesity prevalence}

Obesity trends in children aged 2-4 years are available from IHME for the period 1980-2015 [46] and are the only source of comparable country-level information for children under the age of 5 years. National-level estimates for 1980 and 2015 are shown in Figs. 1 and 2, respectively.

At the global level between 1980 and 2015, the prevalence of obesity increased from 3.9 to $7.2 \%$ in boys and from 3.7 to $6.4 \%$ in girls aged $2-4$ years. In 2015, by far the highest levels of obesity were in American Samoa, where around $50 \%$ of girls and boys in this age group were obese. More than one in three girls were obese in Kiribati and more than one in four in Samoa and Kuwait. For boys, the second highest prevalence of obesity in this age group was in Kuwait, followed by Qatar and Kiribati. For girls, the lowest prevalence of obesity was seen in North Korea, followed by Eritrea, Bangladesh and Burundi. In boys, the lowest prevalence was in Eritrea, followed by North Korea, Burundi and Bangladesh.

Table 3 presents estimates by region. As shown in Figs. 1 and 2, patterns are heterogeneous in sub-Saharan Africa. In 1980, obesity was most common in girls and boys in South Africa and least common in girls and boys in Mali. By 2015, the country with the highest prevalence of obesity in girls was Equatorial Guinea, followed

Table 2 Estimates of the proportion of overweight children under 5 years of age, by region

\begin{tabular}{lll}
\hline Region & $\begin{array}{l}\text { Estimated overweight proportion in } \\
1990(\%)(\text { uncertainty interval) }\end{array}$ & $\begin{array}{l}\text { Estimated overweight proportion (\%) } \\
\text { in 2018 (uncertainty interval) }\end{array}$ \\
\hline Africa & $\mathbf{5 . 2 ( 4 . 2 - 6 . 2 )}$ & $\mathbf{4 . 9}(\mathbf{3 . 6 - 6 . 1 )}$ \\
Northern Africa & $7.0(4.2-11.4)$ & $10.6(4.8-21.8)$ \\
Middle Africa & $4.1(2.2-7.5)$ & $4.6(3.4-6.3)$ \\
Southern Africa & $9.1(6.4-12.9)$ & $13.0(9.3-17.9)$ \\
Eastern Africa & $5.0(3.7-6.7)$ & $4.3(3.5-5.3)$ \\
Western Africa & $3.9(2.8-5.5)$ & $2.1(1.6-2.6)$ \\
Asia & $\mathbf{4 . 0 ( 3 . 0 - 5 . 0 )}$ & $\mathbf{5 . 2}(\mathbf{3 . 9}-\mathbf{6 . 5})$ \\
Eastern Asia & $6.4(5.8-7.0)$ & $\mathbf{6 . 3}(5.5-7.2)$ \\
Western Asia & $5.7(3.0-10.5)$ & $9.0(3.5-21.1)$ \\
Southern Asia & $2.3(0.8-6.1)$ & $3.1(1.9-5.1)$ \\
South-eastern Asia & $1.9(1.5-2.4)$ & $7.7(4.0-14.2)$ \\
Oceania (excluding Australia and New Zealand) & $3.2(2.4-4.2)$ & $9.1(5.9-13.8)$ \\
Latin America and the Caribbean & $\mathbf{6 . 2 ( 4 . 7 - 7 . 7 )}$ & $\mathbf{7 . 5}(\mathbf{6 . 6 - 8 . 4 )}$ \\
Caribbean & $4.2(4.0-4.5)$ & $\mathbf{7 . 0}(3.7-12.8)$ \\
Central America & $5.3(3.7-7.6)$ & $\mathbf{6 . 9}(6.0-8.1)$ \\
South America & $6.8(4.9-9.3)$ & $7.8(6.7-9.1)$
\end{tabular}

Estimates were published jointly by the United Nations Children's Fund (UNICEF), the World Health Organization and the World Bank (see Table 1) Bold shows regional aggregates 


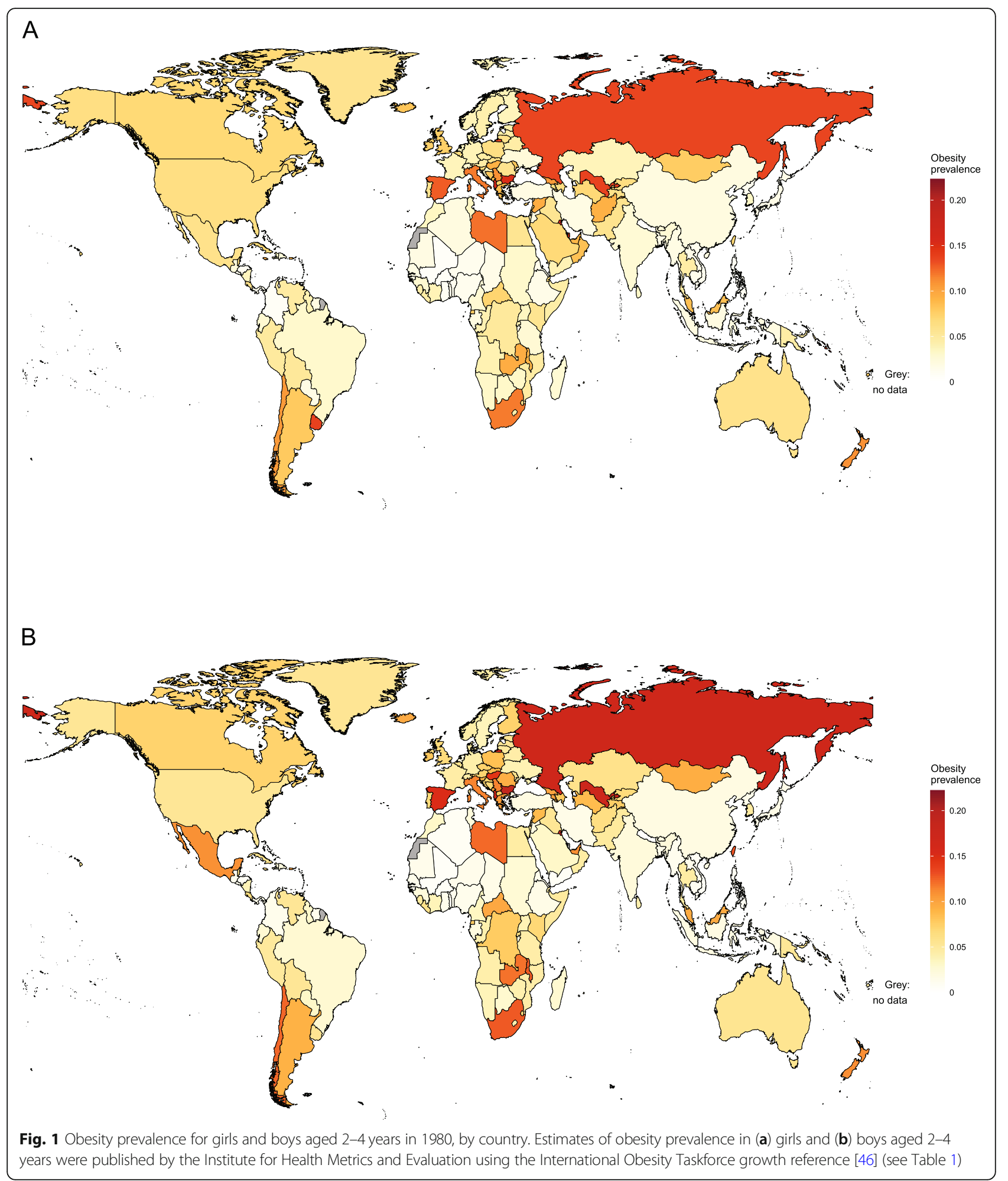

by Djibouti, Zambia and South Africa. Countries with the highest prevalence of obesity in boys were also Equatorial Guinea, followed by Zambia, Djibouti and South Africa. In contrast, less than $2 \%$ of girls in Eritrea and Burundi and less than 1\% of boys in Eritrea were obese.
In south Asia in 1980, the prevalence of obesity was highest in girls and boys in Afghanistan and lowest in girls and boys in Nepal (Fig. 1). By 2015, the highest prevalence of obesity was seen in Bhutan and the lowest in Bangladesh for both sexes (Fig. 2). In 1980 in East 


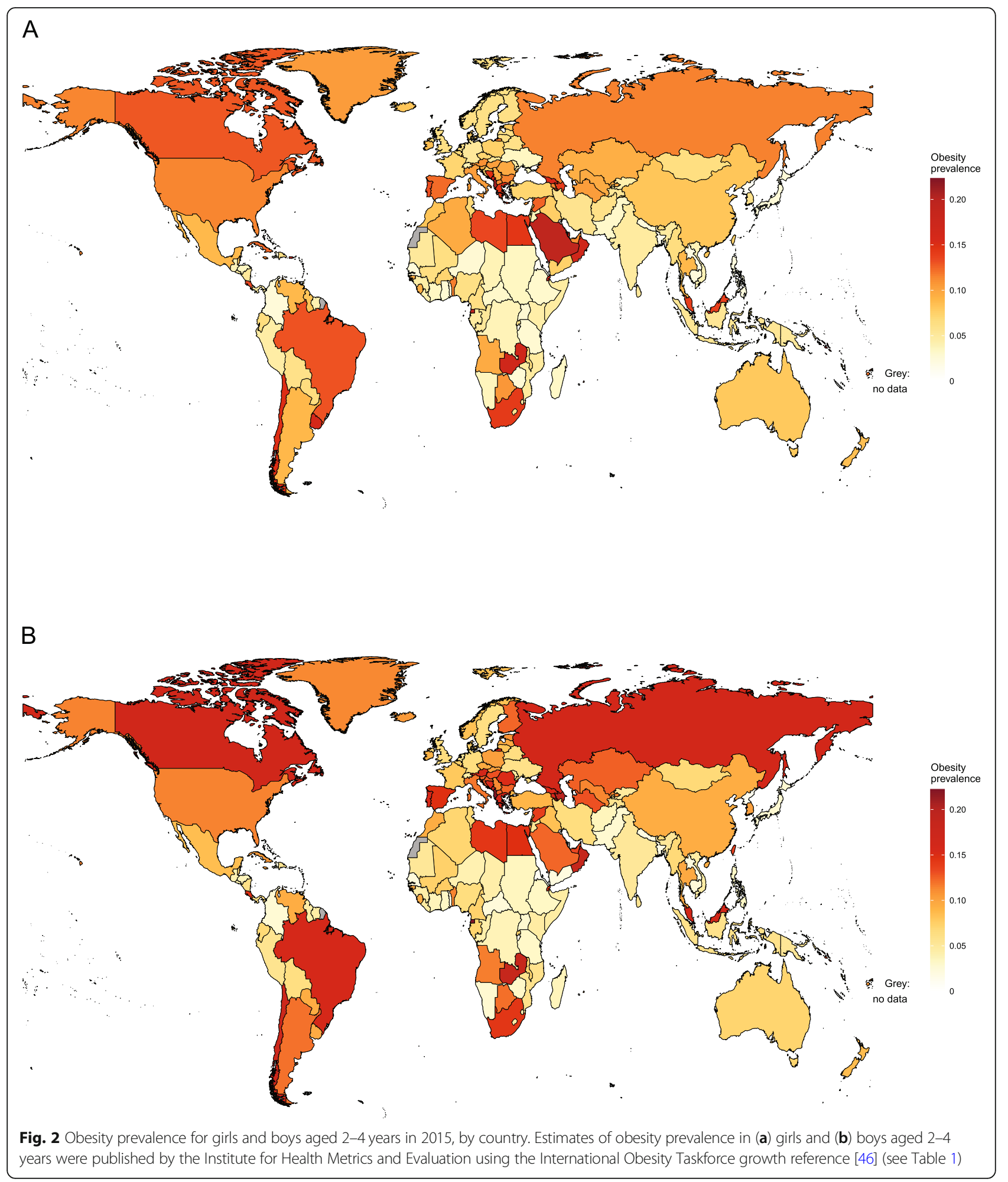

and Southeast Asia, obesity prevalence was highest in girls in Malaysia and boys in Taiwan and was lowest in girls in the Philippines and boys in Vietnam. In 2015, the highest levels of obesity in girls were seen in Malaysia, followed by Thailand and China, while in boys, the highest obesity was also seen in Malaysia, followed by Taiwan and Thailand. North Korea had the lowest level of obesity for both sexes.

Obesity prevalence in children aged 2-4 years was heterogeneous in Oceania. In 1980, while almost half of 
Table 3 Estimates of the proportion of obese children aged 2-4 years, by region

\begin{tabular}{llll}
\hline Region & Sex & $\begin{array}{l}\text { Estimated proportion of obese children } \\
\text { in } 1980(\%) \text { (uncertainty interval) }\end{array}$ & $\begin{array}{l}\text { Estimated proportion of obese children } \\
\text { in 2015 (\%) (uncertainty interval) }\end{array}$ \\
\hline Sub-Saharan Africa & Female & $3.7(3.1-4.4)$ & $5.4(4.5-6.5)$ \\
South Asia & Male & $4.3(3.4-5.5)$ & $5.8(4.7-7.1)$ \\
& Female & $2.8(1.5-4.9)$ & $4.0(2.1-7.1)$ \\
East and Southeast Asia and Oceania & Male & $2.4(1.3-4.2)$ & $4.5(2.3-8.1)$ \\
& Female & $2.3(1.4-3.8)$ & $6.8(4.2-10.8)$ \\
High-income countries & Male & $2.3(1.4-3.7)$ & $8.1(4.8-12.5)$ \\
& Female & $6.0(4.9-7.2)$ & $8.9(7.2-10.9)$ \\
Latin America and the Caribbean & Male & $6.1(4.9-7.6)$ & $10.0(8.0-12.4)$ \\
Middle East and North Africa & Female & $3.9(2.7-5.7)$ & $8.7(6.0-12.4)$ \\
& Male & $5.0(3.2-8.0)$ & $9.8(6.4-14.1)$ \\
Central and Eastern Europe and Central Asia & Female & $9.0(7.3-11.1)$ & $9.2(7.6-10.9)$ \\
& Male & $11.5(9.4-14.1)$ & $8.8(7.3-10.7)$ \\
\hline
\end{tabular}

Estimates were published by the Institute for Health Metrics and Evaluation (see Table 1)

girls and boys in American Samoa were obese, this was the case for fewer than 1 in 20 girls in Papua New Guinea and boys in Fiji. In 2015, obesity ranged from approximately 50\% in American Samoa to around 5\% in Papua New Guinea in both sexes.

In Latin America and the Caribbean in 1980, the highest levels of obesity were seen in girls in Uruguay and boys in Chile. The lowest levels of obesity were seen in girls in Colombia and boys in Honduras. By 2015, the highest levels of obesity were seen in Puerto Rico for both girls and boys. For girls, the next highest levels of obesity were seen in Dominica and Uruguay, while for boys, Puerto Rico was followed by Chile and Barbados. The lowest prevalence of obesity was seen in Haiti and Colombia for both boys and girls.

In the Middle East in 1980, the highest levels of obesity were seen in girls in Kuwait and boys in Qatar, while the lowest levels were seen in girls in Iran and boys in Yemen. By 2015, the highest levels of obesity were seen in girls in Kuwait, Saudi Arabia and Qatar and in boys, in Kuwait, Qatar and Oman. This contrasted with girls in Jordan and boys in Yemen, for whom obesity rates were lowest. In North Africa in 1980, the highest prevalence of obesity was seen in girls and boys in Libya and the lowest prevalence was in girls and boys in Algeria. By 2015, the highest obesity prevalence was seen in girls and boys in Egypt, while the lowest level was in Tunisia for both sexes.

In high-income countries, obesity prevalence increased between 1980 and 2015 (Figs. 1 and 2). In high-income Western countries in 1980, the highest obesity prevalence was in girls in Andorra and boys in Spain, with the lowest levels of obesity in girls in Switzerland and boys in the Netherlands. In 2015, the highest levels of obesity in girls were still in Andorra, followed by Malta, Greece and Portugal. In boys, the highest levels were in Luxembourg, Andorra, Canada and Malta. The lowest levels were in girls and boys in Switzerland. In highincome Asia-Pacific, the highest obesity prevalence in 1980 was seen in girls and boys in Singapore and the lowest in girls and boys in Japan. By 2015, obesity prevalence exceeded 10\% in boys and 6\% in girls in Singapore and South Korea. In contrast, obesity prevalence was less than 3\% in girls and boys in Japan.

In Central and Eastern Europe in 1980, the highest obesity prevalence was seen in girls in Albania and boys in Bulgaria, with the lowest in girls and boys in Ukraine. In 2015, obesity was particularly high in girls in Albania, followed by Montenegro, Bosnia and Herzegovina and Russia. Albania also had the highest prevalence of obesity in boys, followed by Montenegro, Russia and Bosnia and Herzegovina. Obesity prevalence was lowest in girls in Ukraine, followed by Moldova, while in boys, the lowest obesity was in Moldova, followed by Ukraine. In Central Asia in 1980, obesity was most common in girls and boys in Uzbekistan and least common in girls and boys in Kazakhstan. In 2015, the prevalence of obesity was highest in girls in Georgia and boys in Azerbaijan and lowest in both sexes in Kyrgyzstan.

The number of children aged 2-4 years with obesity was also published by IHME for the period 1980-2015 [46]. The division of these children by country in 1980 and 2015 is shown in Figs. 3 and 4, respectively. In 1980, the country with the largest number of girls with obesity was India, followed by China, Russia and the USA. India, China and Russia also had the largest number of boys 


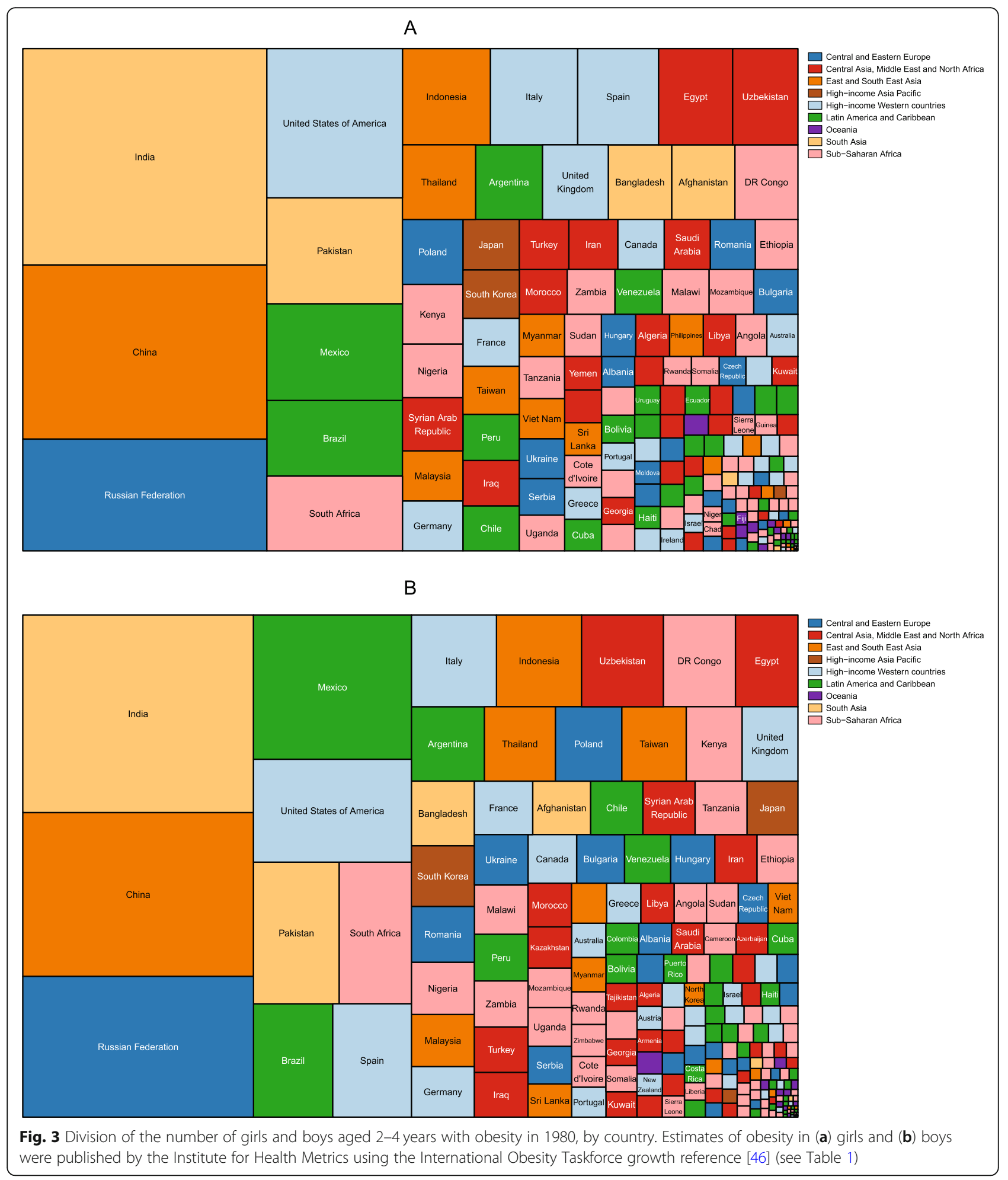

with obesity, followed by Mexico. By 2015, China had the largest number of girls with obesity, followed by India, the USA and Brazil. The largest number of boys with obesity was in China, followed by India, Brazil and the USA.
Children and adolescents aged 5-19 years Worldwide trends in obesity

NCD-RisC holds the largest global database on obesity in children and adolescents aged 5-19 [50]. The most recent estimates, published in 2017, were based on 2416 


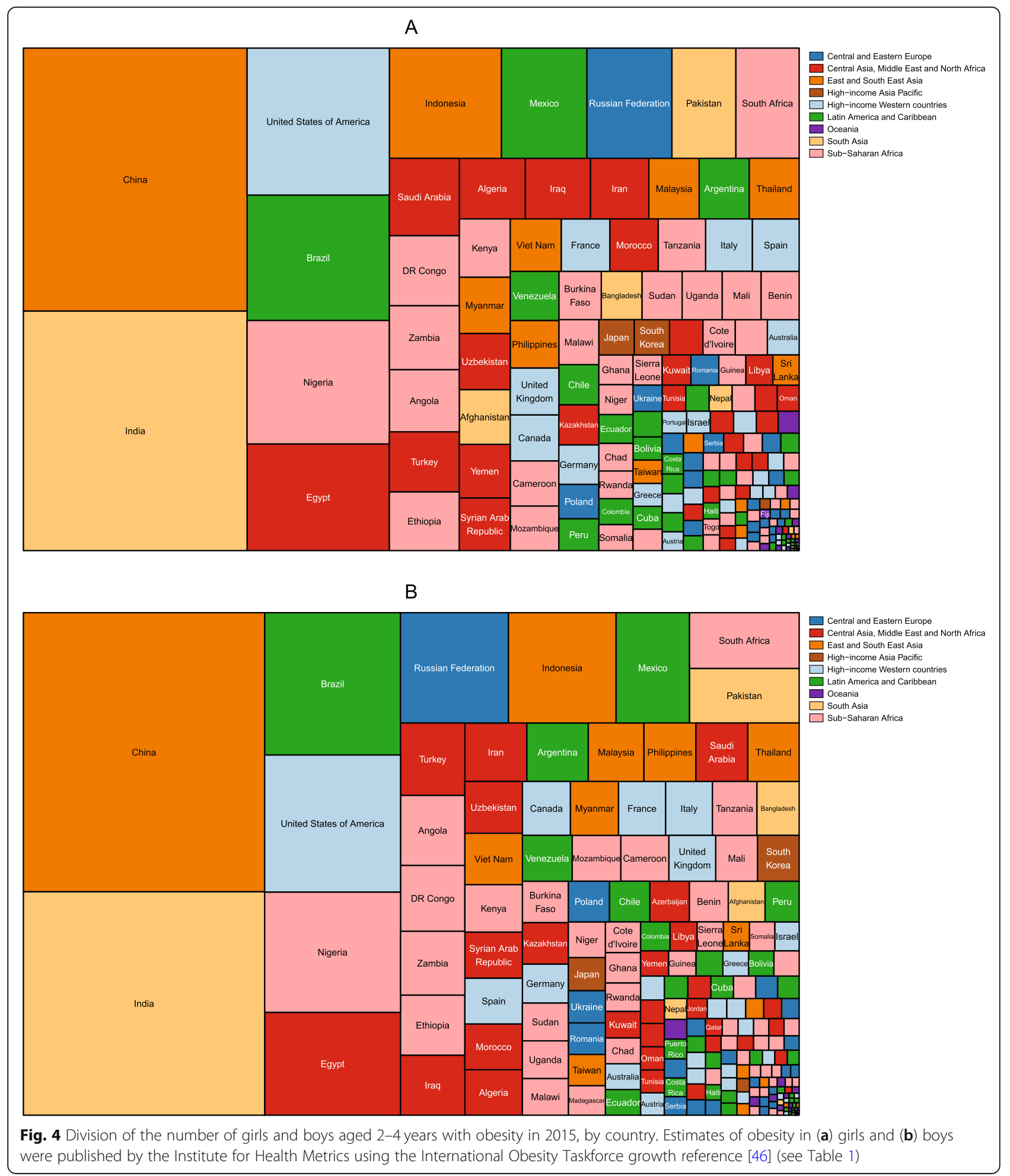

measured data sources [47]. They showed that between 1975 and 2016, obesity prevalence increased from 0.7 to $5.6 \%$ in girls and from 0.9 to $7.8 \%$ in boys. However, the global increase in obesity masked heterogeneous trends at national level, as shown in Figs. 5 and 6.

\section{Obesity trends by region}

Table 4 presents results by region. As shown in Fig. 5, obesity was rare across the world in 1975, but particularly so in sub-Saharan Africa, with an estimated prevalence of $0.1 \%$ for girls and $0.0 \%$ for boys. An obesity 


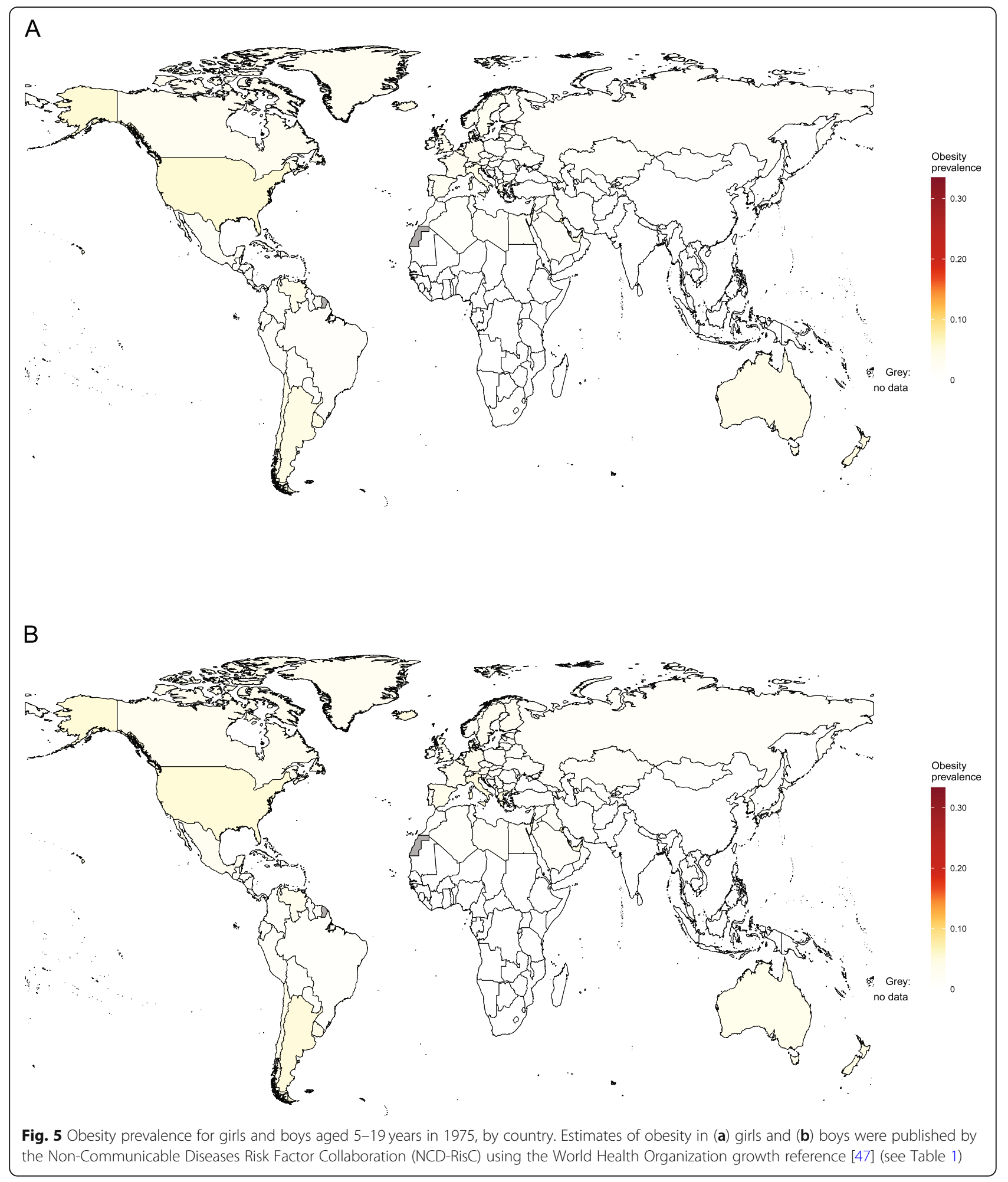

prevalence greater than $0.5 \%$ was observed only in Djibouti and Seychelles for girls and in Seychelles for boys. By 2016, an obesity prevalence of greater than $5 \%$ was seen in 10 countries for girls and two for boys (Fig. 6). Six of the seven countries with the highest rates of obesity in girls were in southern Africa, with South Africa having the highest prevalence and Burkina Faso the lowest prevalence. For boys, Seychelles had the highest prevalence, followed by South Africa and with Uganda having the lowest prevalence. 


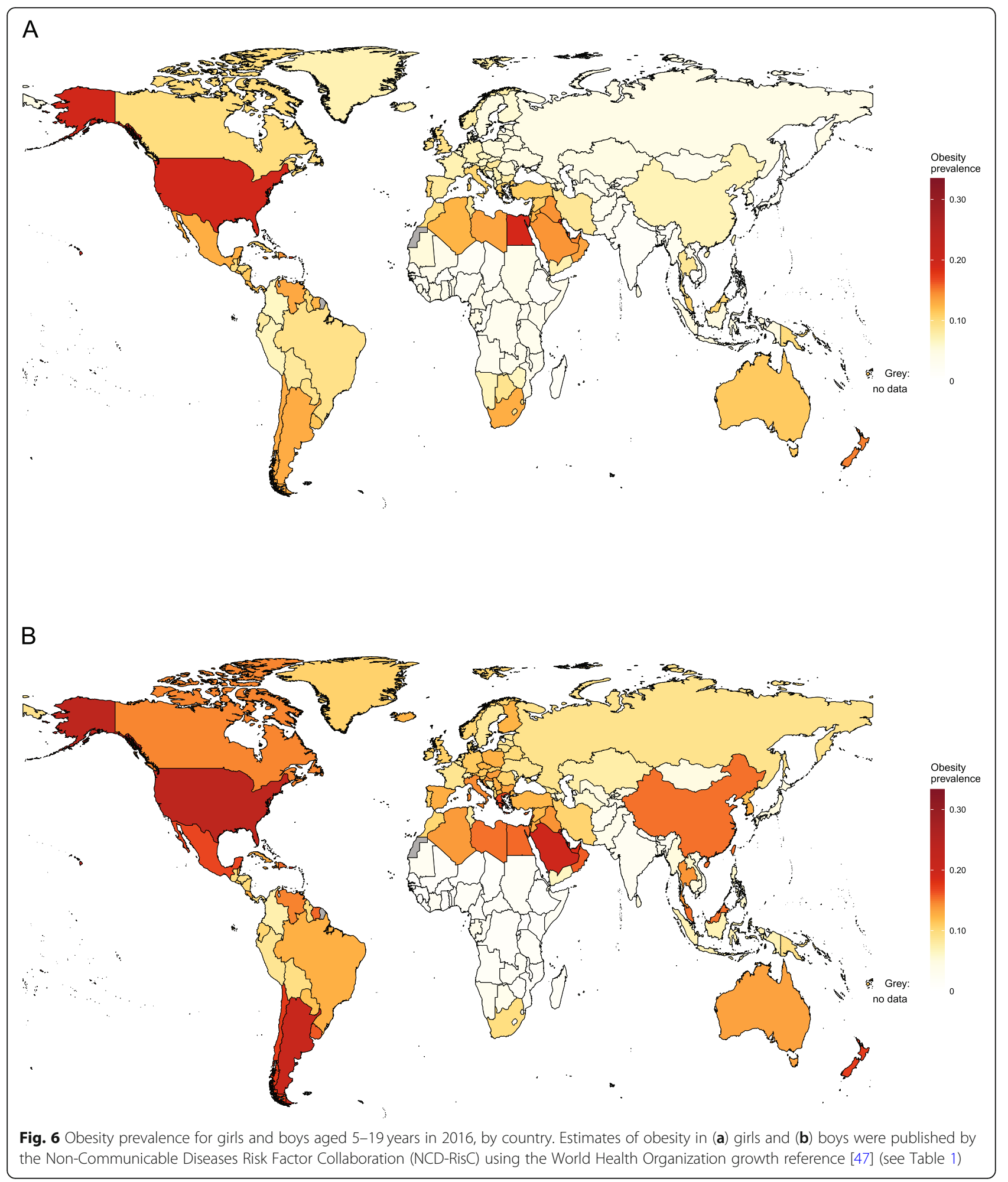

South Asia also had extremely low levels of obesity in 1975, estimated at $0.0 \%$ for both girls and boys and reaching a maximum of $0.1 \%$ for boys in Pakistan. However, obesity was less rare by 2016, with Afghanistan for girls and Bhutan, Pakistan and Bangladesh for boys having a prevalence of obesity of greater than 3\%. More heterogeneous trends were observed in East and Southeast Asia. In 1975, obesity in boys and girls was most common in Hong Kong, but the prevalence of obesity was less than $2 \%$ elsewhere in the region. In 2016, the 
Table 4 Estimates of the proportion of obese children and adolescents aged 5-19years, by region, published by the NonCommunicable Diseases Risk Factor Collaboration (NCD-RisC; see Table 1)

\begin{tabular}{llll}
\hline Region & Sex & $\begin{array}{l}\text { Estimated \% obese children and adolescents } \\
\text { in 1975 (uncertainty interval) }\end{array}$ & $\begin{array}{l}\text { Estimated \% obese children and } \\
\text { adolescents in 2016 (uncertainty interval) }\end{array}$ \\
\hline Sub-Saharan Africa & Female & $0.1(0.0-0.3)$ & $3.2(2.2-4.4)$ \\
South Asia & Male & $0.0(0.0-0.2)$ & $1.7(0.9-2.8)$ \\
East and Southeast Asia & Female & $0.0(0.0-0.1)$ & $1.8(1.0-3.1)$ \\
& Male & $0.0(0.0-0.2)$ & $2.6(1.4-4.5)$ \\
High-income Asia-Pacific & Female & $0.1(0.0-0.2)$ & $5.9(4.2-8.1)$ \\
& Male & $0.2(0.0-0.7)$ & $12.1(9.0-15.7)$ \\
Latin America and the Caribbean & Female & $0.5(0.3-0.9)$ & $2.7(2.0-3.6)$ \\
North Africa, the Middle East and Central Asia & Female & $0.9(0.1-2.5)$ & $7.5(5.9-9.3)$ \\
& Female & $1.6(0.4-3.8)$ & $10.4(7.8-13.6)$ \\
High-income Western countries & Male & $1.8(0.3-4.9)$ & $13.4(10.0-17.2)$ \\
& Female & $3.8(2.1-6.1)$ & $11.3(8.1-15.1)$ \\
Central and Eastern Europe & Male & $4.1(2.3-6.4)$ & $12.0(8.6-15.9)$ \\
Oceania & Female & $0.8(0.1-2.8)$ & $13.3(10.3-16.6)$ \\
& Male & $1.1(0.1-3.5)$ & $16.8(13.2-20.6)$ \\
\hline
\end{tabular}

highest level of obesity in girls was seen in Malaysia and the lowest in Cambodia. For boys, the prevalence of obesity was highest in Brunei Darussalam and lowest in Vietnam. Meanwhile, in high-income countries in Asia-Pacific in 1975, obesity prevalence was highest in Singapore for girls and boys. By 2016, the highest prevalence of obesity was in South Korea and the lowest in Japan for both sexes.

In 1975, obesity levels were low in Latin America and the Caribbean (Fig. 5). Obesity was most common in Bermuda, followed by Argentina and Uruguay for both sexes. By 2016, the prevalence of obesity had become more heterogeneous. For girls, the highest levels of obesity were seen in Puerto Rico, Bermuda and the Bahamas, while for boys the highest levels were seen in Bermuda, Argentina and Puerto Rico. Obesity prevalence was lowest in Colombia for girls and boys, followed by Peru and Haiti for girls and Saint Lucia and Peru for boys.

Heterogeneous trends were observed across North Africa, the Middle East and Central Asia. In 1975, obesity prevalence was highest in girls and boys in Kuwait. By 2016, obesity prevalence was highest in Kuwait and Egypt for girls and in Kuwait and Qatar for boys. Meanwhile, obesity prevalence was lowest in both sexes in Tajikistan.

There were heterogeneous patterns of obesity in highincome Western countries in both 1975 and 2016. In 1975, the highest level of obesity was in Malta for girls and boys, followed by the USA, Andorra and Israel for girls and Andorra, Israel and the USA for boys. Meanwhile, the prevalence of obesity was below $2 \%$ in eight countries for girls and in five countries for boys. By 2016, the highest levels of obesity were observed mostly in English-speaking and Mediterranean countries. The USA had the highest prevalence of obesity for girls and boys, followed by New Zealand. Switzerland had the lowest obesity prevalence among girls and boys.

In 1975, for both sexes, obesity prevalence was less than $2 \%$ in every country in Central and Eastern Europe (Fig. 5). By 2016, the prevalence of obesity had exceeded $13 \%$ in boys and $7 \%$ in girls in Croatia, Hungary and Bulgaria. Obesity prevalence was lowest among boys in Moldova, followed by Bosnia and Herzegovina and the three Baltic states. For girls, Moldova, Russia and Estonia had the lowest prevalence of obesity.

Obesity was uncommon in children and adolescents aged 5-19 years in Oceania in 1975, with prevalence exceeding $5 \%$ only in girls and boys in Nauru and in girls in Palau. By 2016, the 13 countries with the highest obesity rates for girls and the eight countries with the highest obesity rates for boys were all in Oceania; more than $30 \%$ of girls and boys in Nauru, the Cook Islands and Palau were obese. However, there was a contrast between patterns in Melanesia, and Polynesia and Micronesia, with obesity prevalence lower in all countries in Melanesia. 


\section{Changes in obesity at national level}

Between 1980 and 2015, obesity prevalence in every country increased for both sexes, but there was wide variation in the extent of increase. Proportional increases per decade are shown in Fig. 7. For girls, the largest increase in obesity prevalence over time was in Botswana, where obesity increased more than seven-fold per decade, followed by Lesotho and Cambodia, where prevalence increased more than six-fold per decade. In contrast, obesity prevalence only increased by about $10 \%$ per decade in Singapore and Belgium. For boys, the proportional increases were even greater, reaching a peak in Botswana, where obesity increased more than ten-fold per decade. Again, the increase in Singapore was only approximately $10 \%$ per decade.

\section{Numbers of children and adolescents with obesity}

In 1975, there were 5 million girls and 6 million boys aged 5-19 with obesity across the world. The division of these children by country is shown in Fig. 8. In 1975, the USA had the highest number of obese boys and girls aged 5-19, followed by Italy, Mexico and Germany for girls and China, Italy and Mexico for boys. By 2016, the number of children and adolescents aged 5-19 with obesity had increased to 50 million girls and 75 million boys. As shown in Fig. 9, China had the most obese boys and girls, followed by the USA and India.

\section{Gender comparison}

There are clear regional differences in the relationship between obesity level and sex, as shown in Figs. 10 and 11. In 2016, the prevalence of obesity was higher in girls than boys in most countries in sub-Saharan Africa and Oceania, as well as in some other middle-income countries. In contrast, obesity was more common in boys than girls in all high-income countries, and all countries in East and Southeast Asia. Figure 11 shows the absolute numbers of girls and boys with obesity by country; again, clear regional patterns can be seen. In 2016, there were more girls than boys with obesity in almost all countries in subSaharan Africa and in a few other countries, but across the rest of the world, there were more boys than girls with obesity. Substantial differences in the numbers of boys and girls in the general populations of some countries can partly explain this finding. For example, in both China and India in 2016, there were 19 million more 5-19 yearold boys than girls.

\section{Discussion}

Over the past four decades, obesity in children of all ages has increased worldwide, as it has for adults [47]. However, obesity appears to have increased more rapidly in 5-19 year olds than in younger children, with an eight-fold increase between 1975 and 2016. This contrasts with an approximate doubling in obesity rates in children aged 2-4 years between 1980 and 2015, albeit using metrics that are not directly comparable. There is heterogeneity in the levels and trends in obesity prevalence between regions and countries, depending on the stage of the global obesity epidemic they are experiencing. In particular, there has been some flattening of trends, especially among those with high socioeconomic status in high-income countries [51].

The need for high-quality and comparable data is recognised as a key component for monitoring malnutrition [3]. Data from pooled analyses allow examination of change over time and the use of standardised, comparable metrics allows trends to be benchmarked across countries. Here, we have used data from three different sources, covering different ages and countries. This limits their comparability [45-47] and, in particular, there is less standardised and comparable country-level information for children under the age of 5 years [45]. Equally, although national trends are of great interest, it is known that they mask subnational heterogeneity. Collection of disaggregated data at the subnational level and across specific groups of the population is therefore essential to identify groups that are at risk of malnutrition and to ensure progress in meeting global targets [3].

Despite overall increases in the prevalence of obesity in childhood, different forms of malnutrition coexist at global, national and subnational levels. Increases in obesity are linked to a reduction in the prevalence of children of normal weight, without there necessarily being decreases in the prevalence of children who are underweight. At a global level, the prevalence of underweight among children aged 5-19years has remained unchanged over the past four decades [47]. Similar observations have been made in individual countries. For example, in Seychelles, only children in the upper percentiles of body mass index (BMI) have increased in weight, with little or no increase observed among those with median and low BMI [52]. More studies are needed to describe the shift in distribution of BMI over time in populations, e.g. estimates of the whole distribution to examine whether increases in BMI have occurred in all children or only in subgroups.

It is recognised that the main drivers of the current obesity epidemic are related to changing food systems and reduced physical activity [53-55], with two key features. Firstly, there is increased availability of generally inexpensive, energy-dense and ultra-processed foods and beverages. The globalisation of food supply means that it is often economically more profitable to produce and market processed, energy-dense foods than fresh ones. Recent results from the Global Burden of Disease study show that consumption of healthy foods is suboptimal, whereas that of unhealthy options exceeds recommended levels [46]. Secondly, there have been increases 


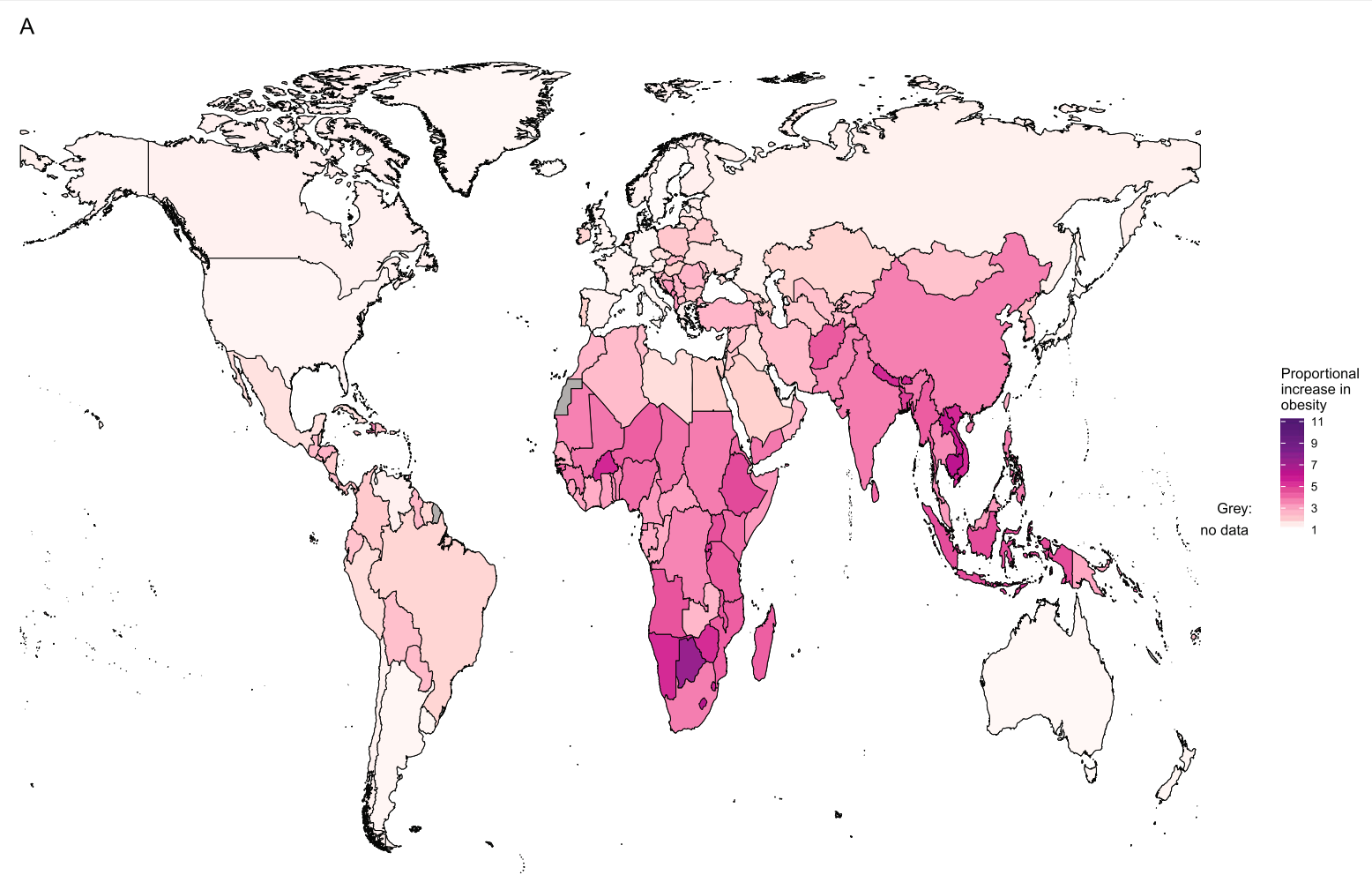

B

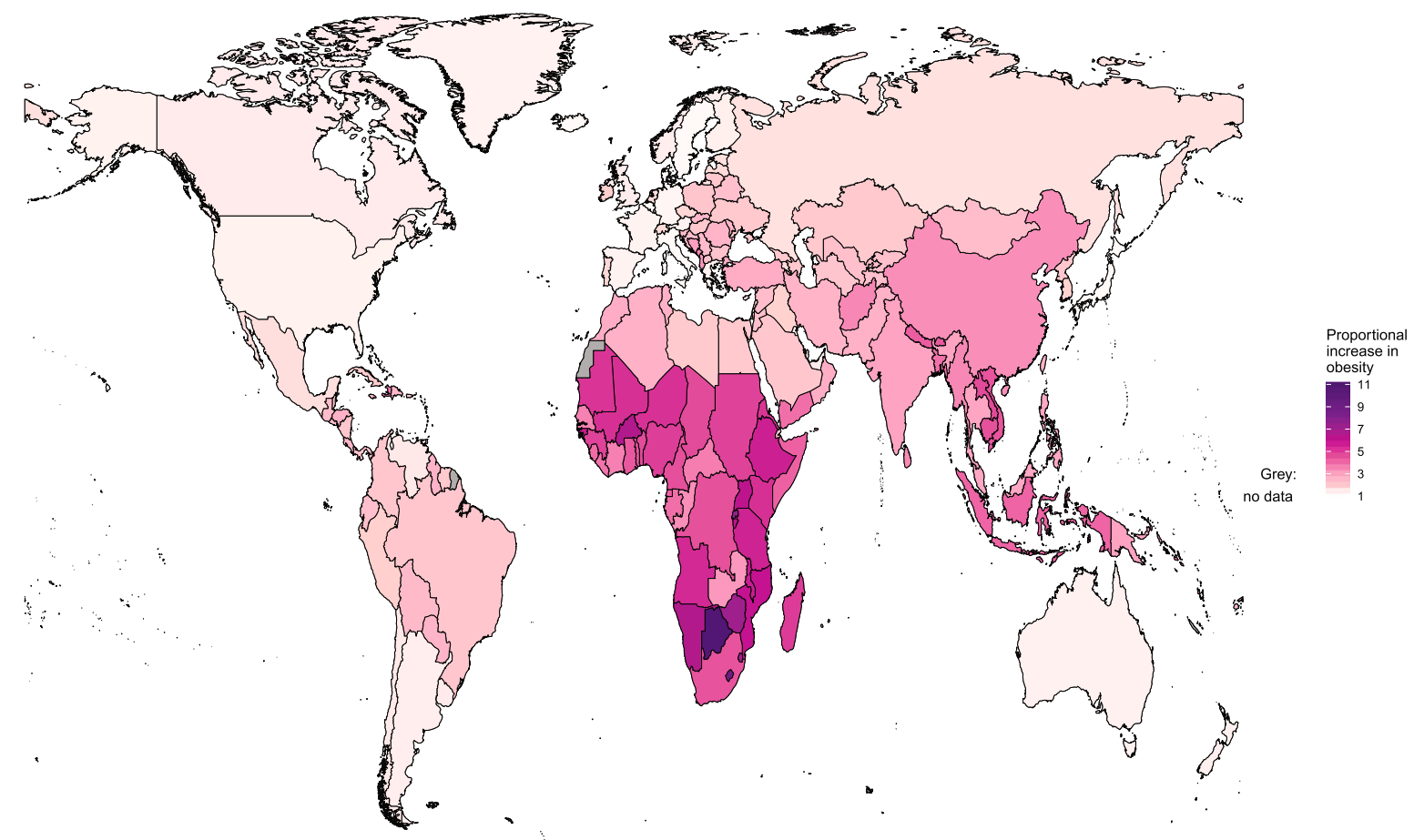

Fig. 7 Proportional increase in obesity for girls and boys aged 5-19years, between 1975 and 2016. Estimates of obesity for (A) girls and (B) boys were published by the Non-Communicable Diseases Risk Factor Collaboration (NCD-RisC) using the World Health Organization growth reference [47] (see Table 1) 


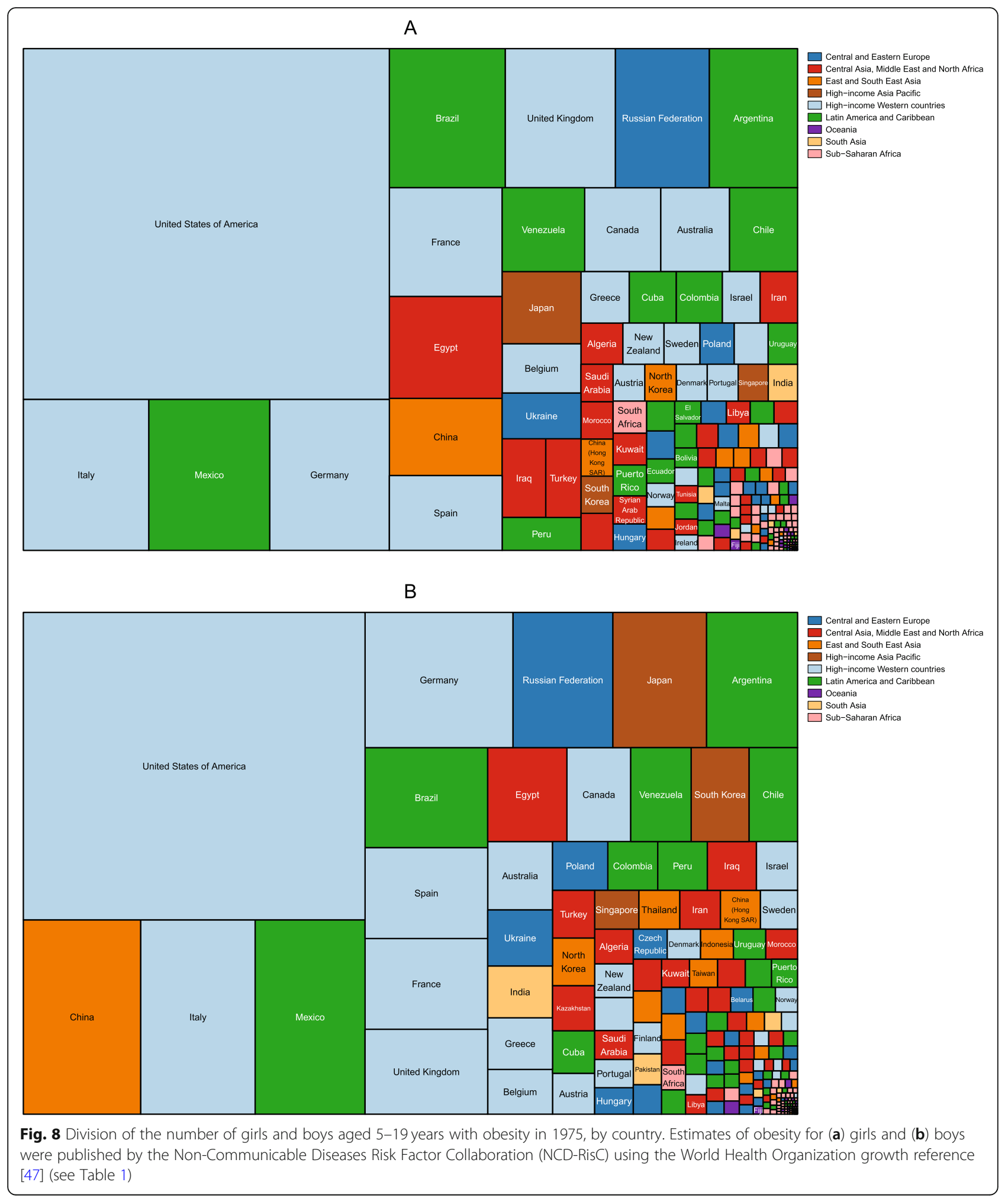

in the number of people with sedentary lifestyles, with high levels of physical inactivity among children [56]. As children transition through childhood and adolescence, susceptibility to the food and physical environments increases. Increasingly, children can choose the foods they eat and how much exercise they do and this has a strong impact on current and future behaviour [57-60]. This may, in part, explain the rapid increase in the 


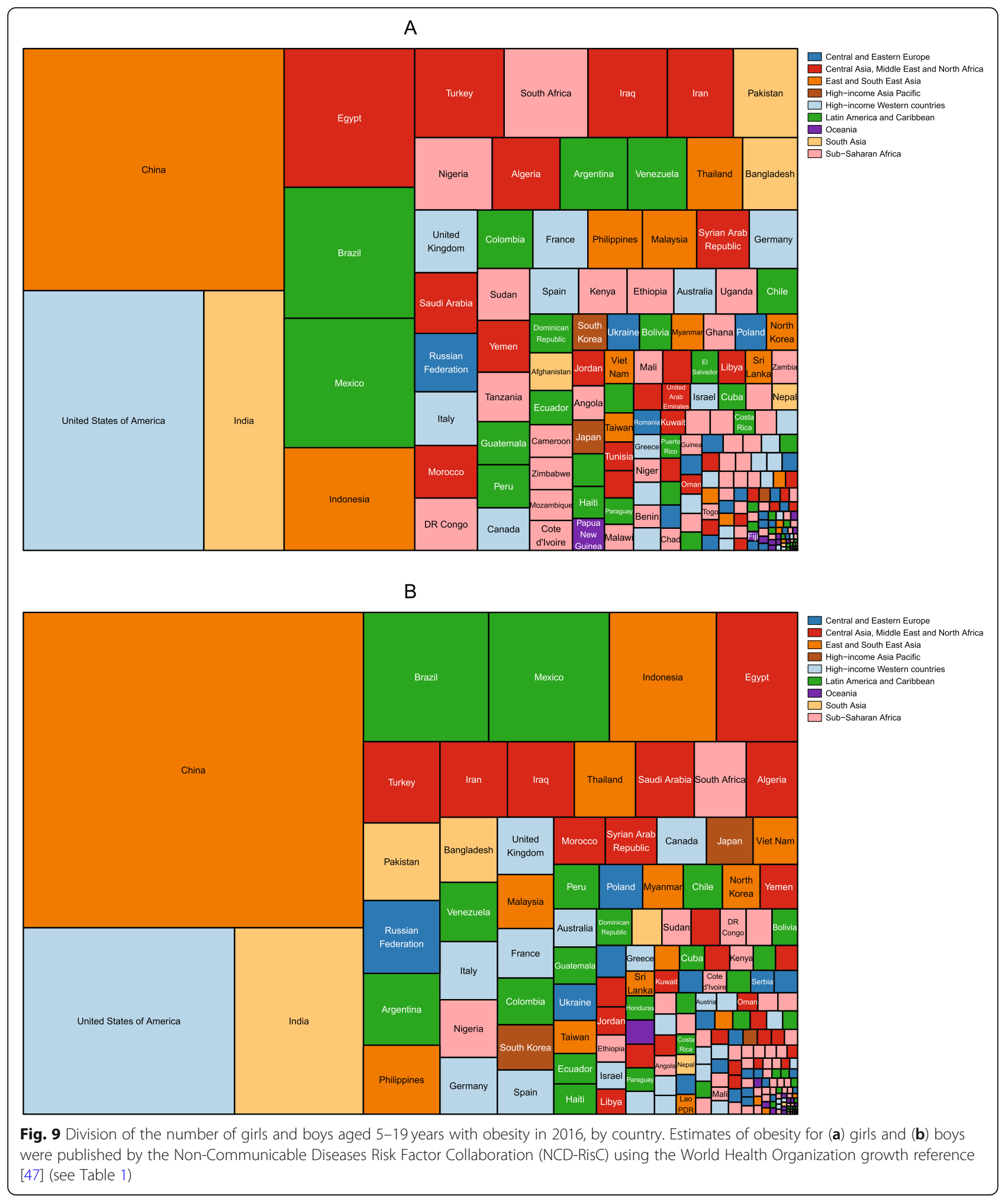

prevalence of obesity in this group. Further investigation is required to explain the more rapid increase in obesity in boys, including studies of whether they are more susceptible to obesogenic pressures.
The need to improve the food environment requires governments, international organisations and other key stakeholders, including civil society and the private sector at local and global levels, to address global and local 


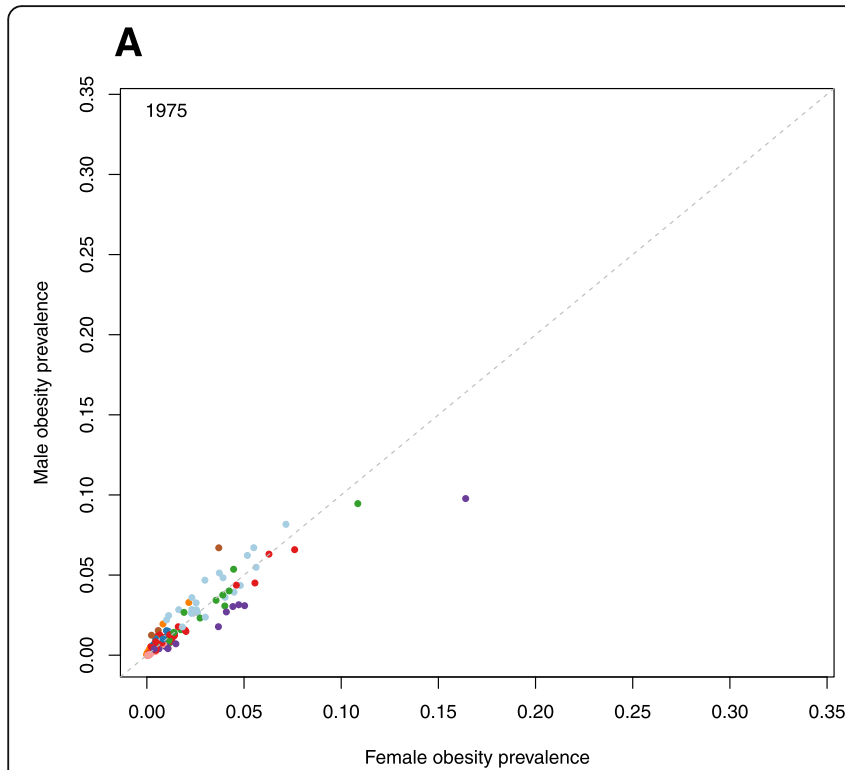

\section{B}

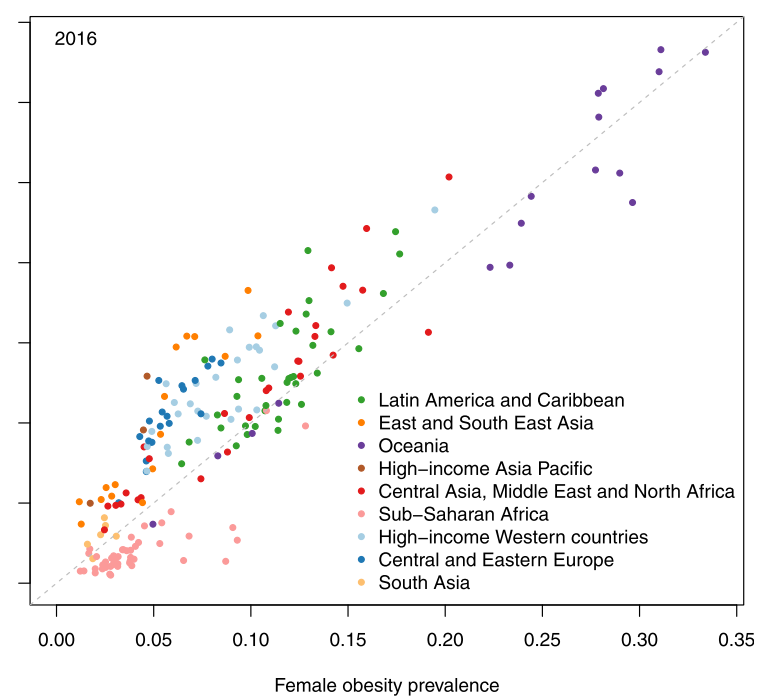

Fig. 10 Comparison of obesity prevalence in girls and boys aged 5-19years in 1975 and 2016. Estimates of obesity in (a) 1975 and (b) 2016 were published by the Non-Communicable Diseases Risk Factor Collaboration (NCD-RisC) using the World Health Organization growth reference [47] (see Table 1)

commercial determinants of obesity, including production and marketing of unhealthy, energy-dense foods and to improve availability and affordability of unprocessed healthy foods. Equally, healthy diets must be integrated with food systems in a sustainable way, such that long-term health benefits are possible [61]. A constructive dialogue with the food industry and effective regulations are needed to improve the availability of healthy foods and reduce that of unhealthy options, including prevention of unethical marketing of unhealthy foods aimed at low-income countries and other vulnerable members of the global population. The paradigm of energy imbalance (increased energy intake not balanced by energy consumption) is often used by the food
A

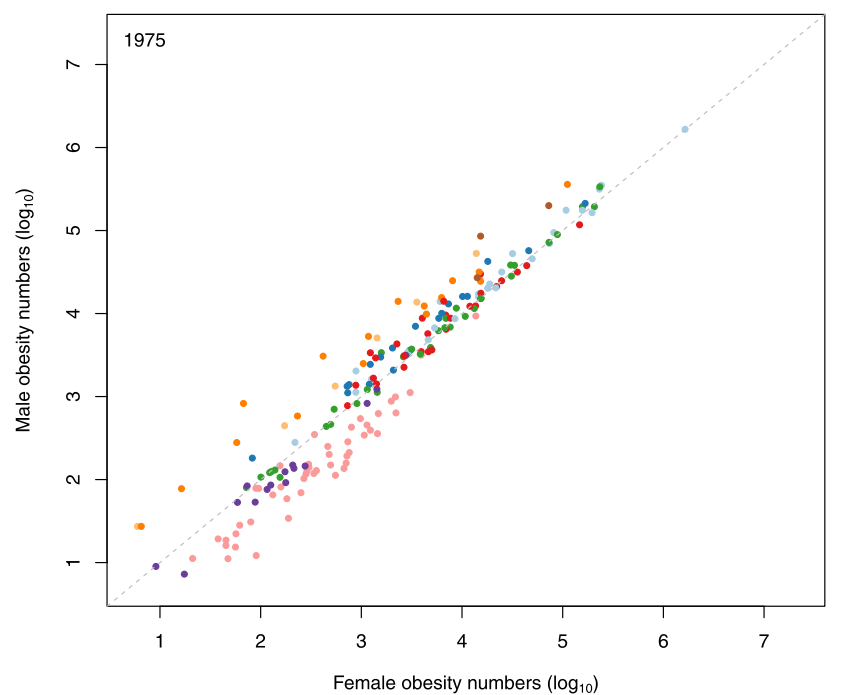

B

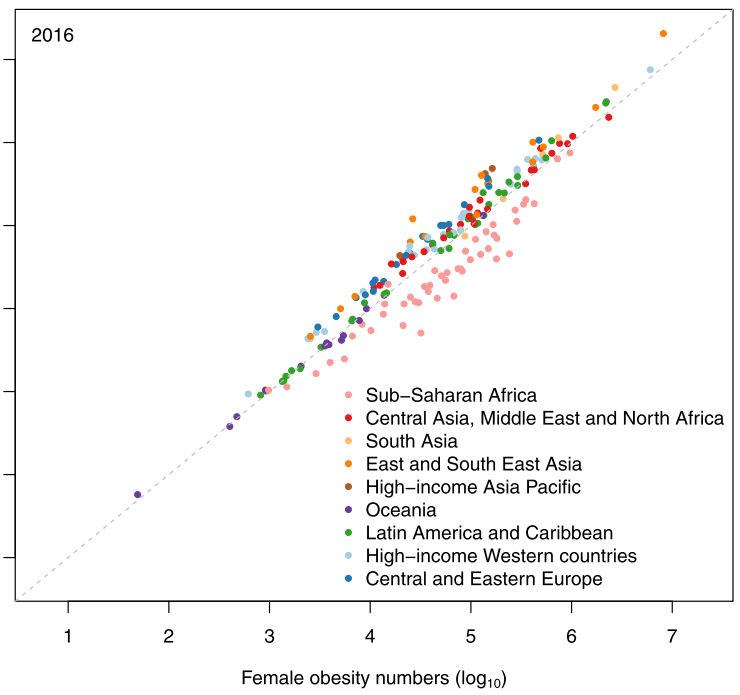

Fig. 11 Comparison of the number of girls and boys aged 5-19years with obesity in 1975 and 2016. Estimates of obesity for (a) 1975 and (b) 2016 were published by the Non-Communicable Diseases Risk Factor Collaboration (NCD-RisC) using the World Health Organization growth reference [47] (see Table 1) 
industry to weaken policies aimed at tackling the use of energy-dense foods; i.e., it is argued that adequate levels of physical activity can compensate for this imbalance. Given the scale of the obesity epidemic, this argument must be viewed with scepticism. In the same vein, city and urban planners must rethink their role in society, given that current physical environments substantially restrict mobility patterns. As sedentarism becomes more common and future jobs require less activity, our children will amass a substantial cumulative burden of inactivity that will become difficult to reverse.

The effectiveness of interventions aimed at children who are overweight and obese has been widely studied [62-65]. Most interventions have targeted behavioural changes, mainly in terms of nutrition and physical activity. There is evidence that some of these interventions have been effective in schools [66, 67]. In particular, promotion of physical activity in schoolbased settings may be beneficial given adequate resources [68], as well as being an important component of effective overweight prevention strategies in children [66]. Efforts to promote active mobility, such as cycling lanes, are being implemented in many cities in high-income countries - and, increasingly in low or middle-income countries, including the cities adhering to the Agita Mundo Network in Latin America [69]. Recently, declines in the level of obesity among pre-school-age children have been observed in New Zealand [70], Leeds (UK) [71, 72] and Amsterdam (the Netherlands) [73]. These declines are associated with interventions aimed at supporting families and communities by creating a healthier food environment and supporting families to enforce healthy habits in children with an approach of shared responsibilities among multiple actors. This may have important implications for future trends of obesity in childhood. However, caution in causal interpretation is necessary and more evidence is needed to establish that the implemented interventions are, in fact, responsible for the observed declines in obesity in childhood [70, 71]. Equally, data and evidence on the effectiveness of community-based approaches are limited compared to school-based programmes [74, 75]. Discussions about the role of community knowledge, attitudes and awareness towards obesity in accepting policy-level solutions continue, but data supporting such evidence are lacking or show unsuccessful examples [76, 77].

Despite this work, the effects of traditional behavioural change interventions will be too small to relieve the global burden of obesity in childhood - at least in the short to medium-term [53]. Community-wide approaches matched with changes in government policies related to food reformulation, advertising and affordability are therefore also required. Policies that can achieve such changes include, among others, excise tax on beverages containing sugar, subsidies or alleviation of trade tax for producing and distributing fruit and vegetables, regulations on food labelling, restrictions on advertising of unhealthy foods and beverages, and incentives or regulations to catalyse reformulation of processed foods toward healthier composition. Other policies include giving vouchers to mothers in the USA with low incomes to purchase fruits and vegetables, low-fat or skimmed milk and whole-grain instead of refined-grain products, among other changes. This has been shown to reduce obesity rates among children aged 2-4 years [78]. However, high levels of heterogeneity in policy are observed across countries, with low and middle-income countries relying more on such approaches (and implementing them earlier) than high-income countries. For example, Mexico was one of the first countries to implement a sugar-sweetened beverage tax; 2 years after implementation, consumption had decreased by $8.2 \%$ [79]. In 2014, Chile started to implement a series of policies aimed at reducing obesity. Tax on beverages with high sugar content was increased from 13 to $18 \%$, while tax on drinks with low or no sugar content was reduced from 13 to $10 \%$. In 2016, a labelling system using black octagons on packaging was introduced for food and beverages that are high in sugar, calories, sodium and saturated fats. In addition, foods and beverages with such labels have been banned from schools, while marketing of these products to children under the age of 14 years is no longer allowed [80, 81]. Initial results suggest a positive impact on knowledge and awareness, reductions in consumption of unhealthy foods and a positive response from the food industry. In turn, the food industry is decreasing the amount of sugar and sodium in some food categories.

The heterogeneity in levels of obesity across the world also has important implications for global targets and goals. It is necessary to aim only for "no increase in obesity by 2025" in those regions and countries in which a clear upward trend in obesity is observed. However, much stronger political action is needed in those regions and countries where the prevalence of obesity has plateaued at high levels, to raise the priority of multi-sectoral interventions to address obesity and other chronic conditions. In general, there is a need to examine how different policy agendas $[5,6,82-84]$ can be integrated and strengthened to promote healthy nutrition and regular physical activity, including preventing overweight among children, while also continuing to implement interventions against undernutrition. This will require additional efforts that should not overlook low and middle-income countries simply 
because some have moderate levels of obesity and high levels of undernutrition.

\section{Conclusions}

Tackling the obesity epidemic in children will require integrated efforts across multiple sectors to provide equitable access to economic resources, education, healthy food and urban environments and to universal health coverage. Most importantly, bolder political will and accountability is needed from actors including government, civil society, academia, the private sector and other key stakeholders, to spearhead efforts to promote production of and access to a healthier environment for all.

\section{Abbreviations}

IHME: Institute for Health Metrics; IOTF: International Obesity Taskforce; NCD: Non-communicable disease; WHO: World Health Organization

\section{Acknowledgements}

Not applicable.

\section{Authors' contributions}

MDC and JB drafted the paper. All other authors contributed to the final version. All authors read and approved the final version of the manuscript.

\section{Funding}

Not applicable.

\section{Availability of data and materials}

Not applicable.

\section{Ethics approval and consent to participate}

Not applicable.

\section{Consent for publication}

Not applicable.

\section{Competing interests}

The authors declare that they have no competing interests.

\begin{abstract}
Author details
${ }^{1}$ Middlesex University, The Burroughs, London NW4 4BT, UK. ²University of Zagreb, Trg Republike Hrvatske 14, 10000 Zagreb, Croatia. ${ }^{3}$ University of Ljubljana, Kongresni trg 12, 1000 Ljubljana, Slovenia. ${ }^{4}$ Center for Primary Care and Public Health, Secteur Croisettes/Bâtiment SC-B, Route de la Corniche 2, 1066 Epalinges, Lausanne, Switzerland. ${ }^{5}$ Ministry of Health, Hospital Road, Victoria, Republic of Seychelles. ${ }^{6}$ Universidad Peruana Cayetano Heredia, Av. Honorio Delgado 430, San Martín de Porres, 15102 Lima, Peru. ${ }^{7}$ Aga Khan University, National Stadium Rd, Karachi 74800, Pakistan. ${ }^{8}$ Independent consultant, Los Angeles, USA. ${ }^{9} \mathrm{C} / \mathrm{O}$ : School of Mathematics, Statistics and Actuarial Science, University of Kent, Giles Lane, Canterbury CT2 7NZ, UK. ${ }^{10}$ ICMR-National Institute of Nutrition, Beside Tarnaka Metro Station, Osmania University PO, Hyderabad, Telangana 500007, India. ${ }^{11}$ South African Medical Research Council, Francie Van Zijl Dr, Parow Valley, Cape Town 7501, South Africa. ${ }^{12}$ University of Kent, Giles Lane, Canterbury CT2 7NZ, UK.
\end{abstract}

Received: 25 April 2019 Accepted: 23 October 2019

Published online: 25 November 2019

\section{References}

1. Lobstein T, Jackson-Leach R, Moodie ML, Hall KD, Gortmaker SL, Swinburn BA, et al. Child and adolescent obesity: part of a bigger picture. Lancet. 2015;385:2510-20.

2. Lobstein T, Baur L, Uauy R. Obesity in children and young people: a crisis in public health. Obes Rev. 2004;5:4-85.
3. Development Initiatives. 2018 Global Nutrition Report: Shining a Light to Spur Action on Nutrition. Bristol: Development Initiatives Poverty Research Ltd; 2018. https://globalnutritionreport.org/. Accessed 2 Apr 2019.

4. World Health Organization (WHO). Comprehensive Implementation Plan on Maternal, Infant and Young Child Nutrition. Geneva: WHO; 2014. https://www. who.int/nutrition/publications/CIP_document/en/. Accessed 18 Oct 2019.

5. World Health Organization (WHO). Global Action Plan for the Prevention and Control of NCDs 2013-2020. Geneva: WHO; 2015. http://www.who.int/ nmh/events/ncd_action_plan/en/. Accessed 2 Apr 2019.

6. World Health Organization (WHO). Nutrition: Global Targets 2025. Geneva: WHO; 2018. http://www.who.int/nutrition/global-target-2025/en/. Accessed 2 Apr 2019.

7. Quek Y-H, Tam WWS, Zhang MWB, Ho RCM. Exploring the association between childhood and adolescent obesity and depression: a meta-analysis. Obes Rev. 2017:18:742-54.

8. Rankin J, Matthews L, Cobley S, Han A, Sanders R, Wiltshire HD, et al. Psychological consequences of childhood obesity: psychiatric comorbidity and prevention. Adolesc Health Med Ther. 2016;7:125-46.

9. Lang JE, Bunnell HT, Hossain MJ, Wysocki T, Lima JJ, Finkel TH, et al. Being overweight or obese and the development of asthma. Pediatrics. 2018;142: e20182119.

10. Visser M, Bouter LM, McQuillan GM, Wener MH, Harris TB. Low-grade systemic inflammation in overweight children. Pediatrics. 2001;107:e13.

11. Schipper HS, Nuboer R, Prop S, van den Ham HJ, de Boer FK, Kesmir Ç, et al. Systemic inflammation in childhood obesity: circulating inflammatory mediators and activated CD14++ monocytes. Diabetologia. 2012;55:2800-10.

12. Uppal V, Mansoor S, Furuya KN. Pediatric non-alcoholic fatty liver disease. Curr Gastroenterol Rep. 2016:18:24.

13. Berardis S, Sokal E. Pediatric non-alcoholic fatty liver disease: an increasing public health issue. Eur J Pediatr. 2014;173:131-9.

14. Smith SM, Sumar B, Dixon KA. Musculoskeletal pain in overweight and obese children. Int J Obes. 2014;38:11-5.

15. Friedemann C, Heneghan C, Mahtani K, Thompson M, Perera R, Ward AM. Cardiovascular disease risk in healthy children and its association with body mass index: systematic review and meta-analysis. BMJ. 2012;345:e4759.

16. World Health Organization (WHO) Consideration of the Evidence on Childhood Obesity for the Commission on Ending Childhood Obesity: Report of the Ad Hoc Working Group on Science and Evidence for Ending Childhood Obesity. Geneva: World Health Organization; 2016.

17. Brady TM. Obesity-related hypertension in children. Front Pediatr. 2017;5:197.

18. Cook S, Kavey RE. Dyslipidemia and pediatric obesity. Pediatr Clin N Am. 2011;58:1363-73.

19. Pulgaron ER, Delamater AM. Obesity and type 2 diabetes in children: epidemiology and treatment. Curr Diab Rep. 2014;14:508

20. Raj M. Obesity and cardiovascular risk in children and adolescents. Indian J Endocr Metab. 2012;16:13-9.

21. Krul M, van der Wouden JC, Schellevis FG, van Suijlekom-Smit LWA, Koes BW. Musculoskeletal problems in overweight and obese children. Ann Fam Med. 2009:7:352-6.

22. Must A, Jacques PF, Dallal GE, Bajema CJ, Dietz WH. Long-term morbidity and mortality of overweight adolescents. A follow-up of the Harvard growth study of 1922 to 1935. N Engl J Med. 1992;327:1350-5.

23. Abdullah A, Wolfe R, Stoelwinder JU, de Courten M, Stevenson C, Walls HL, et al. The number of years lived with obesity and the risk of all-cause and cause-specific mortality. Int J Epidemiol. 2011:40:985-96.

24. Park MH, Falconer C, Viner RM, Kinra S. The impact of childhood obesity on morbidity and mortality in adulthood: a systematic review. Obes Rev. 2012; 13:985-1000.

25. Singh AS, Mulder C, Twisk JWR, Van Mechelen W, Chinapaw MJM. Tracking of childhood overweight into adulthood: a systematic review of the literature. Obes Rev. 2008;9:474-88.

26. Freedman DS, Khan LK, Dietz WH, Srinivasan SR, Berenson GS. Relationship of childhood obesity to coronary heart disease risk factors in adulthood: the Bogalusa heart study. Pediatrics. 2001;108:712-8.

27. Swinburn B, Egger G. Preventive strategies against weight gain and obesity. Obes Rev. 2002:3:289-301.

28. Oken E. Maternal and child obesity: the causal link. Obstet Gynecol Clin N Am. 2009:36:361-77 ix-x.

29. Taveras EM, Rifas-Shiman SL, Belfort MB, Kleinman KP, Oken E, Gillman MW. Weight status in the first 6 months of life and obesity at 3 years of age. Pediatrics. 2009;123:1177-83. 
30. Osei-Assibey G, Dick S, Macdiarmid J, Semple S, Reilly JJ, Ellaway A, et al. The influence of the food environment on overweight and obesity in young children: a systematic review. BMJ Open. 2012;2:e001538.

31. Barros FC, Victora CG, Scherpbier R, Gwatkin D. Socioeconomic inequities in the health and nutrition of children in low/middle income countries. Rev Saude Publica. 2010;44:1-16.

32. Di Cesare M, Khang Y-H, Asaria P, Blakely T, Cowan MJ, Farzadfar F, et al. Inequalities in non-communicable diseases and effective responses. Lancet. 2013:381:585-97.

33. Rogers R, Eagle TF, Sheetz A, Woodward A, Leibowitz R, Song M, et al. The relationship between childhood obesity, low socioeconomic status, and race/ethnicity: lessons from Massachusetts. Child Obes. 2015;11:691-5.

34. Perkins C, DeSousa E. Trends in childhood height and weight, and socioeconomic inequalities. Lancet Public Health. 2018;3:e160-1.

35. Bann D, Johnson W, Li L, Kuh D, Hardy R. Socioeconomic inequalities in childhood and adolescent body-mass index, weight, and height from 1953 to 2015: an analysis of four longitudinal, observational, British birth cohort studies. Lancet Public Health. 2018;3:e194-203.

36. Rhee KE, Phelan S, McCaffery J. Early determinants of obesity: genetic, epigenetic, and in utero influences. Int J Pediatr. 2012;2012:463850.

37. Unnikrishnan R, Anjana RM, Mohan V. Diabetes in south Asians: is the phenotype different? Diabetes. 2014;63:53-5.

38. McGarvey ST. Obesity in Samoans and a perspective on its etiology in Polynesians. Am J Clin Nutr. 1991;53:1586S-94S.

39. Herrera BM, Keildson S, Lindgren CM. Genetics and epigenetics of obesity. Maturitas. 2011:69:41-9.

40. Tremmel M, Gerdtham U-G, Nilsson PM, Saha S. Economic burden of obesity: a systematic literature review. Int J Environ Res. 2017;14:ii: E435.

41. Cawley J. The economics of childhood obesity policy. Health Aff (Millwood). 2010;29:364-71.

42. Cawley J. The impact of obesity on wages. J Hum Resour. 2004;39:451-74.

43. Cawley J, Spiess CK. Obesity and skill attainment in early childhood. Econ Hum Biol. 2008;6:388-97.

44. Finkelstein EA, Graham WCK, Malhotra R. Lifetime direct medical costs of childhood obesity. Pediatrics. 2014;133:854-62

45. World Health Organization (WHO). Global database on child health and malnutrition. UNICEF-WHO-The World Bank: Joint child malnutrition estimates - Levels and trends. Geneva: WHO; 2019. http://www.who.int/ nutgrowthdb/estimates/en/. Accessed 3 Apr 2019

46. The GBD 2015 Obesity Collaborators. Health effects of overweight and obesity in 195 countries over 25 years. N Engl J Med. 2017;377:13-27.

47. NCD Risk Factor Collaboration (NCD-RisC). Worldwide trends in body-mass index, underweight, overweight, and obesity from 1975 to 2016: a pooled analysis of 2416 population-based measurement studies in 128.9 million children, adolescents, and adults. Lancet. 2017:390:2627-42.

48. Cole TJ, Bellizzi MC, Flegal KM, Dietz WH. Establishing a standard definition for child overweight and obesity worldwide: international survey. BMJ. 2000; 320:1240-3.

49. de Onis M, Onyango AW, Borghi E, Siyam A, Nishida C, Siekmann J. Development of a WHO growth reference for school-aged children and adolescents. Bull World Health Organ. 2007;85:660-7.

50. NCD-RisC. NCD Risk Factor Collaboration. http://www.ncdrisc.org/. Accessed 3 Apr 2019.

51. Jaacks LM, Vandevijvere S, Pan A, McGowan CJ, Wallace C, Imamura F, et al. The obesity transition: stages of the global epidemic. Lancet Diabetes Endocrinol. 2019;7:231-40

52. Aly R, Viswanathan B, Mangroo G, Gedeon J, Bovet P. Trends in obesity, overweight, and thinness in children in the Seychelles between 1998 and 2016. Obesity. 2018;26:606-12.

53. Swinburn BA, Sacks G, Hall KD, McPherson K, Finegood DT, Moodie ML, et al. The global obesity pandemic: shaped by global drivers and local environments. Lancet. 2011;378:804-14.

54. Bleich SN, Ku R, Wang YC. Relative contribution of energy intake and energy expenditure to childhood obesity: a review of the literature and directions for future research. Int J Obes. 2011;35:1-15.

55. James WPT. The fundamental drivers of the obesity epidemic. Obes Rev. 2008;9(Suppl 1):6-13.

56. Dollman J. Evidence for secular trends in children's physical activity behaviour. Br J Sports Med. 2005;39:892-7.

57. Hill JO. Understanding and addressing the epidemic of obesity: an energy balance perspective. Endocr Rev. 2006;27:750-61.
58. Sisson SB, Church TS, Martin CK, Tudor-Locke C, Smith SR, Bouchard $C$, et al. Profiles of sedentary behavior in children and adolescents: the US National Health and nutrition examination survey, 2001-2006. Int J Pediatr Obes. 2009:4:353-9.

59. Hardcastle SJ, Thøgersen-Ntoumani C, Chatzisarantis NLD. Food choice and nutrition: a social psychological perspective. Nutrients. 2015;7: 8712-5.

60. Casazza K, Brown A, Astrup A, Bertz F, Baum C, Brown MB, et al. Weighing the evidence of common beliefs in obesity research. Crit Rev Food Sci Nutr. 2015;55:2014-53.

61. Willett W, Rockström J, Loken B, Springmann M, Lang T, Vermeulen S, et al. Food in the Anthropocene: the EAT-Lancet commission on healthy diets from sustainable food systems. Lancet. 2019;393:447-92.

62. Young T, Wiysonge CS, Schoonees A, Shung King M, Uauy R, Kain J. Interventions for preventing obesity in children. Int J Epidemiol. 2014;43:675-8.

63. Wang Y, Cai L, Wu Y, Wilson RF, Weston C, Fawole O, et al. What childhood obesity prevention programmes work? A systematic review and meta-analysis. Obes Rev. 2015;16:547-65.

64. Sobol-Goldberg S, Rabinowitz J, Gross R. School-based obesity prevention programs: a meta-analysis of randomized controlled trials. Obesity. 2013;21:2422-8.

65. Kelley GA, Kelley KS, Pate RR. Exercise and BMI in overweight and obese children and adolescents: a systematic review and trial sequential metaanalysis. Biomed Res Int. 2015;2015:704539.

66. Bleich SN, Vercammen KA, Zatz LY, Frelier JM, Ebbeling CB, Peeters A. Interventions to prevent global childhood overweight and obesity: a systematic review. Lancet Diabetes Endocrinol. 2018;6:332-46.

67. Story M, Nanney MS, Schwartz MB. Schools and obesity prevention: creating school environments and policies to promote healthy eating and physical activity. Milbank Q. 2009:87:71-100.

68. Dobbins M, De Corby K, Robeson P, Husson H, Tirilis D. School-based physical activity programs for promoting physical activity and fitness in children and adolescents aged 6-18. Cochrane Database Syst Rev. 2009;21:CD007651.

69. Matsudo VKR, Lambert EV. Bright spots, physical activity investments that work: Agita Mundo global network. Br J Sports Med. 2017;51:1382-3.

70. Gibb S, Shackleton N, Audas R, Taylor B, Swinburn B, Zhu T, et al. Child obesity prevalence across communities in New Zealand: 20102016. Aust N Z J Public Health. 2019;43:176-81.

71. Thornton J. What's behind reduced child obesity in Leeds? BMJ. 2019; $365: 12045$

72. Rudolf M, Perera R, Swanston D, Burberry J, Roberts K, Jebb S. Observational analysis of disparities in obesity in children in the UK: has Leeds bucked the trend? Pediatr Obes. 2019;14:e12529.

73. Gemeente Amsterdam. Programmainformatie Aanpak Gezond Gewicht. https://www.amsterdam.nl/bestuur-organisatie/organisatie/sociaal/ onderwijs-jeugd-zorg/zo-blijven-wij/programma. Accessed 19 Jul 2019.

74. Messing S, Rütten A, Abu-Omar K, Ungerer-Röhrich U, Goodwin L, Burlacu l, et al. How can physical activity be promoted among children and adolescents? A systematic review of reviews across settings. Front Public Health. 2019;7:55.

75. Brown T, Moore TH, Hooper L, Gao Y, Zayegh A, ljaz S, et al. Interventions for preventing obesity in children. Cochrane Database Syst Rev. 2019;7: CD001871.

76. Wakefield MA, Loken B, Hornik RC. Use of mass media campaigns to change health behaviour. Lancet. 2010;376:1261-71.

77. Community Preventive Services Task Force. Stand-alone mass media campaigns to increase physical activity: updated findings from the community preventive services task force. Am J Prev Med. 2012;43: $562-4$.

78. Daepp MIG, Gortmaker SL, Wang YC, Long MW, Kenney EL. WIC food package changes: trends in childhood obesity prevalence. Pediatrics. 2019; 143:e20182841.

79. Colchero MA, Rivera-Dommarco J, Popkin BM, Ng SW. In Mexico, evidence of sustained consumer response two years after implementing a sugarsweetened beverage tax. Health Aff (Milwood). 2017;36:564-71.

80. Rodríguez Osiac L, Cofré C, Pizarro T, Mansilla C, Herrera CA, Burrows $J$, et al. Using evidence-informed policies to tackle overweight and obesity in Chile. Rev Panam Salud Publica. 2017;41:e156. 
81. Organisation for Economic Co-operation and Development (OECD). OECD Reviews of Public Health: Chile: A Healthier Tomorrow. Paris: OECD Publishing; 2019.

82. World Health Organization (WHO). Global Action Plan on Physical Activity 2018-2030: More Active People for a Healthier World. Geneva: WHO; 2019.

83. Nutrition for Growth. https://nutritionforgrowth.org/. Accessed 10 Apr 2019.

84. 1,000 Days. https://thousanddays.org/. Accessed 10 Apr 2019.

\section{Publisher's Note}

Springer Nature remains neutral with regard to jurisdictional claims in published maps and institutional affiliations.

Ready to submit your research? Choose BMC and benefit from:

- fast, convenient online submission

- thorough peer review by experienced researchers in your field

- rapid publication on acceptance

- support for research data, including large and complex data types

- gold Open Access which fosters wider collaboration and increased citations

- maximum visibility for your research: over $100 \mathrm{M}$ website views per year

At BMC, research is always in progress.

Learn more biomedcentral.com/submissions 